\title{
ANALISIS ETOS KERJA, LINGKUNGAN KERJA DAN BEBAN KERJA TERHADAP KEPUASAN KERJA PEGAWAI (Survey Pada Pegawai UPTD Puskesmas Bangkinang Kota)
}

\author{
Zulher \\ Sekolah Tinggi Ilmu Ekonomi Bangkinang \\ Email : zulher.stiebkn@gmail.com
}

\begin{abstract}
This study aims to determine the effect of work ethic, work environment and work load on employee job satisfaction at UPTD Puskesmas Bangkinang Kota. Work ethic is a work spirit that is owned by someone to be able to work more in order to obtain value for their lives. The work environment is all the facilities and infrastructure that are around a person who can influence the implementation of their work. Workload is a group or a number of activities that must be completed by an organizational unit or position holder within a certain period of time and job satisfaction is a pleasant or unpleasant situation in which someone views their work. The analysis in this study uses multiple analysis with 64 respondents. Sampling uses the census method, while the hypothesis testing in this study uses the ftest and t test. Based on the results of the study it can be concluded that simultaneously and partially, work ethic, environment and workload significantly influence job satisfaction.
\end{abstract}

Keywords: Job Stress, Motivation, and Performance

Abstrak: Penelitian ini bertujuan untuk mengetahui pengaruh etos kerja, lingkungan kerja dan beban kerja terhadap kepuasan kerja karyawan di UPTD Puskesmas Bangkinang Kota. Etos kerja adalah semangat kerja yang dimiliki oleh seseorang untuk dapat bekerja lebih banyak untuk mendapatkan nilai bagi kehidupannya. Lingkungan kerja adalah semua fasilitas dan infrastruktur yang ada di sekitar seseorang yang dapat mempengaruhi pelaksanaan pekerjaan mereka. Beban kerja adalah kelompok atau sejumlah kegiatan yang harus diselesaikan oleh unit organisasi atau pemegang posisi dalam periode waktu tertentu dan kepuasan kerja adalah situasi yang menyenangkan atau tidak menyenangkan di mana seseorang memandang pekerjaan mereka. Analisis dalam penelitian ini menggunakan analisis berganda dengan 64 responden. Pengambilan sampel menggunakan metode sensus, sedangkan pengujian hipotesis dalam penelitian ini menggunakan uji f dan uji t. Berdasarkan hasil penelitian dapat disimpulkan bahwa secara simultan dan parsial, etos kerja, lingkungan dan beban kerja berpengaruh signifikan terhadap kepuasan kerja.

Kata kunci: Stres Kerja, Motivasi, dan Kinerja

\section{A. PENDAHULUAN}

Pembangunan kesehatan di Indonesia bertujuan untuk meningkatkan kesadaran, kemauan dan kemampuan hidup sehat bagi setiap orang agar dapat mewujudkan derajat kesehatan yang setinggi - tingginya sebagai perwujudan kesejahteraan umum sebagai yang dimaksud dalam Pembukaan Undang-Undang Dasar 1945. Pelayanan kesehatan adalah setiap upaya yang diselenggarakan sendiri atau secara bersama-sama dalam suatu organisasi untuk memelihara dan meningkatkan kesehatan, mencegah dan menyembuhkan penyakit serta memulihkan kesehatan perorangan, keluarga, kelompok ataupun masyarakat (Depkes RI, 2009).

Puskesmas adalah ujung tombak pelayanan kesehatan untuk menunjang keberhasilan pelaksanaan program di Dinas Kesehatan dalam upaya mencapai Visi Indonesia Sehat. Keberhasilan pencapaian Visi Indonesia Sehat sangat dipengaruhi oleh penataan dan pengelolaan tenaga kesehatan untuk melaksanakan kegiatan pokok puskesmas. Salah satu sasaran penting dalam manajemen sumber daya manusia pada suatu organisasi adalah terciptanya kepuasan kerja. Demikian pula di Unit Pelaksana Teknis Dinas (UPTD) Puskesmas Bangkinang Kota merupakan 
salah satu unit pelayanan teknis dari Dinas Kesehatan Kabupaten Kampar. Sebagai (UPTD) Kabupaten/Kota Puskesmas berperan menyelenggarakan sebagian dari tugas teknis operasional Dinas Kesehatan Kabupaten/Kota dan merupakan unit pelaksana tingkat pertama serta ujung tombak pembangunan kesehatan di Bangkinang Kota.

Kepuasan kerja merupakan perasaan senang seseorang terhadap pekerjaan itu sendiri. Yang memang sesuai dengan latar belakang bidang pendidikannya sehingga mampu mengerjakan dan menyelesaikan pekerjaan dan tugas yang dihadapinya dengan maksimal. Sebaliknya jika pegawai yang tidak mendapatkan kepuasan kerja akan merasa jenuh dengan tuntutan yang diberikan oleh atasan, sehingga pekerjaan pun akan terhambat dan cara penyelesaiannya tidak akan maksimal. Salah satu permasalahan penting dalam organisasi ini adalah bagaimana organisasi dapat menciptakan situasi agar pegawai dapat memperoleh kepuasan kerja secara individu dengan baik dan bagaimana cara supaya mereka mau bekerja secara maksimal. Beberapa faktor yang mempengauhi kepuasan kerja antara lain adalah etos kerja, lingkungan kerja dan beban kerja.

Salah satu faktor yang mempengaruhi kepuasan kerja adalah etos kerja. Menurut Sinamo (2011:42) etos kerja adalah seperangkat prilaku kerja positif yang berakar pada kerjasama yang kental, komitmen yang fundamental, disertai komitmen yang total pada paradigma kerja yang integral. Etos kerja juga merupakan kepercayaan seseorang pada sikap dan perilaku dalam pekerjaannya, karena akan membuka pandangan dan sikap manusia untuk menilai tinggi terhadap kerja keras dan sungguh-sungguh, sehingga dapat mengikis sikap kerja yang asal-asalan. Berdasarkan hasil wawancara penulis dengan beberapa pegawai pada UPTD Puskesmas Bangkinang Kota sebagai narasumber menyatakan bahwa mereka memiliki etos kerja yang baik seperti sikap saling membantu satu sama lain. Dalam melayani masyarakat, pembagian kerja pada UPTD Puskesmas Bangkinang Kota adalah dengan sistim pembagian shift sesuai dengan peraturan yang berlaku yaitu shift masing-masing pegawai mendapat jadwal 6 jam sehari, sehingga pelayanan kepada masyarakat tetap berjalan dengan baik.

Faktor kedua yang mempengaruhi kepuasan kerja adalah lingkungan kerja. Lingkungan kerja menurut Sedarmayanti (2011:12) adalah kondisi lingkungan kerja bisa disebut baik atau sesuai jika manusia bisa menjalankan aktivitas dengan optimal, sehat, aman dan nyaman. Kesesuaian lingkungan kerja bisa dilihat dari dalam jangka waktu yang lama lebih jauh dari lingkungan-lingkungan kerja yang kurang baik bisa menuntut tenaga kerja dan waktu yang lebih banyak dan tidak mendukung didapatkannya rancangan sistem kerja yang efisien.Lingkungan yang sesuai dapat memberikan kesan nyaman dan berfungsi sebagai sarana yang harus diperhatikan terhadap efektivitas dan efisensi kerja, sedangkan lingkungan kerja yang tidak baik dapat mengakibatkan terjadinya kecelakaan di unit-unit produksi yang pada akhirnya secara keseluruhan akan menurunkan tingkat pelayanan pegawai.

Berdasarkan wawancara prapenelitian yang penulis dapatkan dari pegawai di UPTD Puskesmas Bangkinang Kota lingkungan kerja pegawai tersebut adalah suasana lingkungan kerja yang kurang nyaman, ruang poli yang masih terbatas dan sempit, kemudian kurangnya sarana prasarana sepreti kursi dan meja ruang tunggu masih kurang sehingga menyebabkan antrian pasien yang kurang nyaman.

Faktor selanjutnya adalah beban kerja, menurut Sunarso (2010:133)Beban kerja adalah sekumpulan atau sejumlah kegiatan yang harus diselesaikan oleh suatu unit organisasi atau pemegang jabatan dalam jangka waktu tertentu.Beban kerja sangat penting bagi sebuah organisasi. Dengan pemberian beban kerja yang efektif organisasi dapat mengetahui sejauh mana pegawainya dapat diberikan beban kerja yang maksimal dan sejauh mana dapat berpengaruh terhadap kepuasan pegawai maupun organisasi itu sendiri. Berdasarkan wawancara dengan beberapa pegawai UPTD Puskesmas Bangkinang Kota berikut jumlah pegawai dan kunjungan pasien pada UPTD Puskesmas Bangkinang Kota tahun 2014 sampai tahun 2018 sebagaimana terlihat pada Tabel 1: 
Tabel 1

Jumlah Pegawai dan Kunjungan Pasien pada UPTD Puskesmas Bangkinang Kota Tahun 2014 sampai tahun 2018

\begin{tabular}{|c|c|c|}
\hline Tahun & $\begin{array}{c}\text { Jumlah Pegawai } \\
\text { (Orang) }\end{array}$ & $\begin{array}{c}\text { Jumlah Kunjungan Pasien } \\
\text { (Orang) }\end{array}$ \\
\hline 2014 & 61 & 16.480 \\
\hline 2015 & 64 & 15.440 \\
\hline 2016 & 67 & 18.034 \\
\hline 2017 & 68 & 15.436 \\
\hline 2018 & 64 & 17.010 \\
\hline
\end{tabular}

Sumber : UPTD Puskesmas Bangkinang Kota tahun, 2019

Dari Tabel 1 dapat dilihat bahwa jumlah kunjungan pasien yang ada pada UPTD Puskesmas Bangkinang Kotaberfluktuasi. Jumlah kunjungan pasien menurun pada tahun 2015 dan tahun 2017. Hal ini disebabkan karena kesadaran masyarakat akan kesehatan sudah membaik. Sedangkan pada tahun 2018 jumlah kunjungan pasien meningkat sebanyak 17.010 pasien.Hal ini disebabkan oleh adanya efek dari perkembangan program Badan Penyelenggaraan Jaminan Sosial (BPJS) Kesehatan, sehingga masyarakat tidak lagi memikirkan soal biaya. Dengan meningkatnya jumlah kunjungan pasien pada UPTD Puskesmas Bangkinang Kota maka UPTD Puskesmas Bangkinang Kota membutuhkan pegawai yang handal dalam melayani dan menangani masyarakat. Beban kerja yang terlalu berat dapat menyebabkan pegawai mudah jenuh dan kelelahan fisik dalam bekerja, sementara beban kerja yang monoton dapat menyebabkan pegawai merasa bosan serta lebih bermalas malasan dan bersantai dalam pekerjaannya sehingga menurunnya kepuasan kerja.

Berdasarkan uraian diatas maka rumusan masalah penelitian ini adalah bagaimana pengaruh etos kerja, lingkungan kerja dan beban kerja terhadap kepuasan kerja pegawai (Survey pada pegawai UPTD Puskesmas Bangkinang Kota).Tujuan yang diteliti adalah untuk mengetahui pengaruh etos kerja, lingkungan kerja dan beban kerja terhadap kepuasan kerja pegawai (Survey pada pegawai UPTD Puskesmas Bangkinang Kota).

\section{Kepuasan Kerja}

Menurut Robbins (2010:189) kepuasan kerja adalah sikap umum terhadap pekerjaan seseorang yang menunjukan perbedaan antara jumlah penghargaan yang diterima pekerja dan jumlah yang mereka yakini seharusnya mereka terima. Handoko (2011:81) mengemukakan bahwa kepuasan kerja adalah keadaan emosional yang menyenangkan atau tidak menyenangkan dengan mana karyawan memandang pekerjaan mereka. Seseorang yang tingkat kepuasan tinggi memiliki perasaan positif tentang pekerjaannya, sementara sesorang yang tidak puas akan pekerjaannya memiliki perasaan negatif pada pekerjaannya. Dapat disimpulkan dari berbagai pendapat bahwa kepuasan kerja merupakan kepuasan kerja yang menikmati pekerjaanya dengan mendapatkan pujian, perlakuan, posisi, sarana, upah serta lingkungan kerja yang baik.

\section{Etos Kerja}

Etos kerja menjadi salah satu aspek penting karena merupakan proses yang dipersyaratkan, sehingga diharapkan mendapat tenaga kerja yang sesuai dengan jabatan yang didudukinya. Dalam etos kerja pegawai perlu diperhatikan apakah sudah sesuai dengan yang diharapkan instansi/organisasi.

Menurut Sinamo (2011:53) mengartikannya etos kerja sebagai seperangkat perilaku positif yang berakar pada keyakinan yang disertai komitmen total paradigma kerja. Harsono \& Santoso (2010:79) menyatakan bahwaetos kerja adalah semangat kerja yang didasari oleh nilai-nilai atau norma-norma tertentu. Selanjutnya menurut Sukriyanto (2010:37) yang menyatakan bahwa etos 
kerja adalah suatu semangat kerja yang dimiliki oleh masyarakat untuk mampu bekerja lebih guna memperoleh nilai hidup mereka.

\section{Lingkungan Kerja}

Menurut Sunyoto (2015:38) lingkungan kerja merupakan komponen yang sangat penting ketika karyawan melakukan aktivitas bekerja. Dengan memperhatikan lingkungan kerja yang baik atau menciptakan kondisi kerja yang mampu memberikan motivasi untuk bekerja, maka akan membawa pengaruh terhadap kinerja karyawan dalam bekerja.Sutrisno (2009:116) lingkungan kerja adalah keseluruhan sarana dan prasarana kerja yang ada di sekitar karyawan yang sedang melakukan pekerjaan yang dapat mempengaruhi pelaksanaan pekerjaan. Lingkungan kerja meliputi tempat bekerja, fasilitas dan alat bantu pekerjaan, kebersihan, pencahayaan, ketenangan, termasuk juga hubungan kerja antara orang-orang yang ada ditempat tersebut.

\section{Beban Kerja}

Beban kerja merupakan sekumpulan atau sejumlah kegiatan yang harus diselesaikan oleh suatu unit organisasi atau pemegang jabatan dalam jangka waktu tertentu. Beban kerja dapat berupa tuntutan tugas atau pekerjaan, organisasi, dan lingkungan kerja. Ali (2010:63) beban kerja adalah sesuatu yang terasa memberatkan, barang-barang atau sesuatu yang dipikul, yang sukar untuk dikerjakan sebagai tanggungan. Robbins (2010:160) didefinisikan sebagai suatu proses dimana individu mengorganisasikan dan menafsirkan kesan indera mereka agar memberi makna kepada lingkungan mereka. Dari definisi diatas dapat disimpulkan bahwa beban kerja adalah besaran pekerjaan yang harus dipikul oleh suatu jabatan atau unit organisasi dan merupakan hasil kali antara volume kerja dan norma waktu.

\section{Hipotesis}

Hipotesis dalam penelitian ini adalah diduga etos kerja, lingungan kerja dan beban kerja berpengaruh secara simultan dan parsial terhadap kepuasan kerja pegawai UPTD Puskesmas Bangkinang Kota.

\section{Definisi Operasional Variabel Penelitian}

Variabel penelitian ini adalah :

1. Kepuasan kerja $(\mathrm{Y})$ adalah keadaan yang menyenangkan atau tidak menyenangkan dimana para karyawan memandang pekerjaan mereka (Robbins, 2015:188). Indikator dari variabel ini adalah pekerjaan yang secara mental menantang, kondisi kerja yang mendukung, gaji atau upah yang pantas, rekan sekerja yang mendukung, kesesuaian, pengawasan.

2. Etos kerja $\left(\mathrm{X}_{1}\right)$ adalahseperangkat perilaku positif yang berakar pada keyakinan yang disertai komitmen total paradigma kerja (Sinamo, 2011:45). Indikator dari variabel ini adalah amanah, panggilan, aktualisasi, ibadah, seni, pelayanan.

3. Lingkungan kerja $\left(\mathrm{X}_{2}\right)$ adalah suatu tempat yang terdapat sejumlah kelompok dimana di dalamnya terdapat beberapa fasilitas pendukung untuk mencapai tujuan perusahaan sesuai visi dan misi perusahaan(Sedarmayanti, 2011:26). Indikator dari variabel ini adalah sirkulasi udara, pencahayaan diruang kerja, kebisingan, kasilitas, hubungan pegawai, keamanan kerja.

4. Beban kerja $\left(\mathrm{X}_{3}\right)$ sesuatu yang dirasakan berada di luar kemampuan pekerja untuk melakukan pekerjaannya (Putra.2012:22). Indikator dari variabel ini adalah target yang harus dicapai, kondisi pekerjaan, standar pekerjaan, lingkungan pekerjaan, penggunaan waktu, tanggung jawab. 


\section{B. METODE PENELITIAN}

Tempat penelitian ini dilakukan di UPTD Puskesmas Bangkinang Kota, Kabupaten Kampar, Provinsi Riau. Waktupenelitian ini dilakukan pada bulan Agustus 2019 hingga Oktober 2019. Jenis data yang digunakan adalah data primer dan sekunder. Teknik pengumpulan data yang digunakan adalah observasifile researchdan kuesioner. Populasi dalam penelitian ini adalah seluruhpegawai negeri sipil (PNS) yang bekerja di UPTD Puskesmas Bangkinang Kota pada tahun 2019 yang berjumlah 64 orang, sedangkan sampel diambil dari seluruh populasi yang dijadikan sampel menggunakan metode sensus yaitu teknik penentuan sampel bila semua anggota populasi digunakan sebagai sampel (Sugiyono, 2011:85). Sehingga yang menjadisampel dalam penelitian ini adalah sebanyak 64 orang responden.Analisa data pada penelitian ini dilakukan dengan model persamaan regresi linear berganda dengan persamaan sebagai berikut :

$Y=\alpha+\beta_{1} X_{1}+\beta_{2} X_{2}+\beta_{3} X_{3} \varepsilon$

Keterangan: $Y=$ Kepuasan kerja, $\alpha=$ konstanta sebagai titik potong, $\beta_{1}, \beta_{2}, \beta_{3}=$ Koefisien Regresi, $\mathrm{X}_{1}=$ Etos kerja, $\mathrm{X}_{2}=$ Lingkungan Kerja, $\mathrm{X}_{3}$ Etos Kerja dan $\varepsilon=$ Error Term. Selanjutnya pengujian hipotesis pada penelitian ini menggunakan uji $\mathrm{F}$ dan uji $\mathrm{t}$ dengan alpha $5 \%$.

\section{HASIL DAN PEMBAHASAN}

Hasil pengolahan data dapat dilihat pada Tabel 2 berikut:

Tabel 2

Hasil Analisa Regresi Linear Berganda Coefficients $^{\mathrm{a}}$

\begin{tabular}{|c|c|c|c|}
\hline & \multirow{2}{*}{ Model } & \multicolumn{2}{|c|}{ Unstandardized Coefficients } \\
\hline & & B & Std. Error \\
\hline & (Constant) & 6,490 & 2,929 \\
\hline & Etos Kerja & ,312 & ,143 \\
\hline 1 & Lingkungan Kerja & , 176 & 079 \\
\hline & Beban Kerja & ,335 & 119 \\
\hline
\end{tabular}

a. Dependent Variable: Kepuasan Kerja

\section{Sumber : Data olahan, 2019}

Berdasarkan tabel 2 diatas adalah hasil pengujian hipotesis persamaan linear berganda dapat disajikan dalam bersamaan berikut ini :

$\mathrm{Y}=6,490+0,312 \mathrm{X}_{1}+0,176 \mathrm{X}_{2}+0,355 \mathrm{X}_{3}$

Nilai konstanta $(\alpha)$ adalah bernilai positif 6,490 artinyaetos kerja, lingkungan kerjadan beban kerja bernilai 0 (nol), maka kepuasan kerja akan tetap ada sebesar 6,490.Nilai koefisien regresi variabel etos kerja $(\beta 1)$ bernilai positif yaitu 0,312 , artinya setiap peningkatan variabel etos kerja sebesar 1 satuan akan meningkatkan kepuasan kerja sebesar 0,312 dengan asumsi variabel lain konstan dan begitu juga sebaliknya.Nilai koefisien regresi variabel lingkungan kerja $(\beta 2)$ bernilai positif yaitu 0,176 , artinya setiap peningkatan variabel lingkungan kerja sebesar 1 satuan akan meningkatkankepuasan kerjasebesar 0,176 dengan asumsi variabel lain konstan dan begitu juga sebaliknya.Nilai koefisien regresi variabel beban kerja ( $\beta 3$ ) bernilai positif yaitu 0,355 , artinya setiap peningkatan variabel beban kerja sebesar 1 satuan akan meningkatkankepuasan kerjasebesar 0,355 dengan asumsi variabel lain konstan dan begitu juga sebaliknya. 


\section{Hasil Uji Hipotesis Secara Simultan ( Uji F )}

Adapun hasil pengujian hipotesis secara simultan dapat dilihat pada Tabel3.

Tabel 3

Hasil Uji Hipotesis Secara Simultan (Uji F)

ANOVA ${ }^{\mathrm{a}}$

\begin{tabular}{|c|c|c|c|c|c|c|}
\hline & Model & $\begin{array}{c}\text { Sum of } \\
\text { Squares }\end{array}$ & df & $\begin{array}{c}\text { Mean } \\
\text { Square }\end{array}$ & $\mathbf{F}$ & Sig. \\
\hline \multirow{3}{*}{1} & Regression & 1858,477 & 3 & \multirow{3}{*}{$\begin{array}{r}619,492 \\
12,646\end{array}$} & \multirow[t]{3}{*}{48,987} & \multirow[t]{3}{*}{, $000^{b}$} \\
\hline & Residual & 758,757 & 60 & & & \\
\hline & Total & 2617,234 & 63 & & & \\
\hline
\end{tabular}

a. Dependent Variable: Kepuasan Kerja

b. Predictors: (Constant), Etos Kerja, Lingkungan Kerja, Beban Kerja

Sumber : Data olahan, 2019

Berdasarkan tabel 3 diatas diketahui bahwa nilai signifikansi ketiga variabel bebas bernilai 0,000 yang mana nilai tersebut lebih kecil dari 0,050, artinya variabeletos kerja, lingkungan kerjadan beban kerja secara bersama-sama berpengaruh signifikan terhadap variabel kepuasan kerja.

\section{Hasil Uji Hipotesis Secara Parsial (Uji t)}

Hasil uji hipotesis secara parsial, yakni pengaruh skill dan knowledge dapat dilihat padaTabel4berikut :

Tabel4

Hasil Uji Hipotesis Secara Parsial (Ujit)

\begin{tabular}{|l|l|r|r|}
\hline \multicolumn{2}{|c|}{ Model } & \multicolumn{1}{|c|}{ t } & \multicolumn{1}{c|}{ Sig. } \\
\hline \multirow{4}{*}{1} & Constant) & 2,216 &, 031 \\
\cline { 2 - 4 } & Etos Kerja & 2,179 &, 033 \\
\cline { 2 - 4 } & Lingkungan Kerja & 2,222 &, 030 \\
\cline { 2 - 4 } & Beban Kerja & 2,806 &, 007 \\
\hline
\end{tabular}

a. Dependent Variable: Kepuasan Kerja

Sumber : Data olahan, 2019

Variabel etos kerja $\left(\mathrm{X}_{1}\right)$ memperoleh nilai t hitung sebesar 2,179 dengan nilai signifikan sebesar 0,033. Dengan demikian nilai signifikansi t hitung variabel etos kerja lebih rendah dari alpha, artinya terdapat pengaruh yang signifikan dari variabel etos kerjaterhadap kepuasan kerjaPegawai pada UPTD Puskesmas Bangkinang Kota. Variabel lingkungan kerja $\left(\mathrm{X}_{1}\right)$ memperoleh nilai $t$ higung sebesar 2,222 dengan nilai signifikan sebesar 0,030. Dengan demikian nilai signifikansi t hitung variabel lingkungan kerja lebih rendah dari alpha, artinya terdapat pengaruh yang signifikan dari variabel lingkungan kerjaterhadap kepuasan kerjaPegawai pada UPTD Puskesmas Bangkinang Kota. Variabel beban kerja $\left(\mathrm{X}_{3}\right)$ memperoleh nilai t hitung sebesar 2,806 dengan nilai signifikan sebesar 0,007. Dengan demikian nilai signifikansi t hitung variabel beban kerja lebih rendah dari alpha, artinya terdapat pengaruh variabel beban kerja terhadap kepuasan kerjaPegawai pada UPTD Puskesmas Bangkinang Kota.

\section{PENUTUP}

1. Variabel etos kerja, lingkungan kerja dan beban kerja secara simultan terhadap kepuasan kerjaPegawai pada UPTD Puskesmas Bangkinang Kota.

2. Variabel etos kerja, lingkungan kerja dan beban kerja secara parsial terhadap kepuasan kerjaPegawai pada UPTD Puskesmas Bangkinang Kota. 


\section{E. DAFTAR PUSTAKA}

Ali, Z. 2010, Pengantar Keperawatan Keluarga. Penerbit EGC, Jakarta.

Departemen Kesehatan Republik Indonesia, DepKes RI tahun 2009. Tentang Penyelenggaraan Pelayanan Kesehatan Dasar Digaris Depan. Jakarta.

Handoko, T. Hani. 2011. Manajemen Personalia dan Sumberdaya Manusia. Penerbit Penerbit BPFE, Yogyakarta.

Harsono. \&Santoso . 2010. Perencanaan Kepegawaian. Penerbit Fokus Media, Bandung.

Robbins, Stephen P \& Coulter, Mary. 2010. Manajemen Edisi Kesepuluh. Penerbit Erlangga, Jakarta.

Sedarmayanti. 2011. Manajemen Sumber Daya Manusia, Reformasi Birokrasi dan Manajemen Pegawai Negeri Sipil, Cetakan Kelima, Penerbit PT. Refika Aditama, Bandung

Sinamo, Jansen. 2011. 8 Etos Kerja Profesional. Penerbit Institut Dharma Mahardika, Jakarta.

Sugiyono. 2011.Metode Penelitian Kuantitatif dan Kualitatif dan $R \& D$. Penerbit CV Alfabeta, Bandung.

Sunarso. 2010. Pengaruh Kepemimpinan, Kedisiplinan, Beban Kerjadan Motivasi Kerja Terhadap Kinerja Guru Sekolah. Jurnal Managemen Sumber Daya Manusia.Universitas Dian Nuswantoro Semarang.

Sunyoto, Danang.(2015). Manajemen dan Pengembangan Sumber Daya Manusia. Penerbit Center for Academic Publishing Service, Yogyakarta.

Sutrisno, Edy. 2015. Manajemen Sumber Daya Manusia (Cetakan Ketujuh). Penerbit Kencana Prenada Media Group, Jakarta. 